\title{
Investigations of Printed Flexible pH Sensing Materials Based on Graphene Platelets and Submicron $\mathrm{RuO}_{2}$ Powders
}

\author{
Daniel Janczak, ${ }^{1}$ Andrzej Peplowski, ${ }^{1}$ Grzegorz Wroblewski, ${ }^{1}$ Lukasz Gorski, ${ }^{2}$ \\ Elzbieta Zwierkowska, ${ }^{3}$ and Malgorzata Jakubowska ${ }^{1}$ \\ ${ }^{1}$ Institute of Metrology and Biomedical Engineering, Warsaw University of Technology, A. Boboli 8, 02-525 Warsaw, Poland \\ ${ }^{2}$ Institute of Biotechnology, Warsaw University of Technology, Noakowskiego 3, 00-664 Warsaw, Poland \\ ${ }^{3}$ Institute of Electronic Materials Technology, Wolczynska 133, 01-919 Warsaw, Poland \\ Correspondence should be addressed to Malgorzata Jakubowska; maljakub@mchtr.pw.edu.pl
}

Received 5 December 2016; Revised 1 February 2017; Accepted 16 February 2017; Published 6 March 2017

Academic Editor: Sher Bahadar Khan

Copyright (C) 2017 Daniel Janczak et al. This is an open access article distributed under the Creative Commons Attribution License, which permits unrestricted use, distribution, and reproduction in any medium, provided the original work is properly cited.

\begin{abstract}
The paper describes the investigations of $\mathrm{pH}$-sensitive materials for screen printed flexible $\mathrm{pH}$ sensors. The sensors were fully printed and consisted of three layers, conductive made of low temperature-curable silver paste, insulating made of UVcurable dielectric paste, and $\mathrm{pH}$-sensitive made of developed graphene/ruthenium oxide pastes. Graphene and ruthenium oxide composites were prepared with different proportions of graphene nanoplatelets paste and submicron ruthenium dioxide. To perform functional measurements, particular testing sensors were fabricated on flexible polyester foil. Afterwards electrochemical potential measurements of fabricated devices were carried out. Sensors were also exposed to cyclic bending and the change of $\mathrm{pH}$ sensitivity before and after bending was described. Eventually, percolation threshold concerning the amount of ruthenium oxide in the $\mathrm{pH}$-sensitive layer was designated and UV influence on the sensitivity was observed that together allow for optimization of sensors' fabrication costs.
\end{abstract}

\section{Introduction}

Printed electronics is a rapidly growing field of technology strongly investigated by both the research institutions and companies seeking for new products. Printed electronics has a lot of benefits such as easy processing without the need for vacuum, clean rooms, or high temperatures. The possibility of low temperature processing made this technology advisable for applications using flexible materials, such as polymer foils [1], papers [2], and fabrics [3]. Electronic devices may be fabricated with printing processes, such as screen printing [4], flexography [5], ink-jet printing [6], gravure [7], or pad printing [8] which are well known from graphics industry. Thanks to novel materials suitable for electronics there are vast possibilities of fabrication of functional printings, such as conductive [9], resistive [10], dielectric [11], or sensitive layers [12]. Those printable materials may be used for fabrication of electronic elements, such as conductive paths [13], antennas [14], capacitors [15], resistors [16], heaters [17], light sources [18], or diverse sensors [19].
Measuring the proton activity $(\mathrm{pH})$ of environment is one of the basic chemical measurements required in various fields of human interest, like biotechnology [20], medicine [21], environmental science [22], water-support system monitoring [23], food safety [24], and many others. Apart from direct $\mathrm{pH}$ measurement, sensors detecting proton activity can be employed as a basis for modification, for example, with enzymes [25], nucleic acids [26], or microorganisms [27], yielding biosensors for even more applications. Given this need for sensing of $\mathrm{pH}$ and $\mathrm{pH}$-affecting markers or reactions, improvement and development of appropriate production technologies is a relevant task for research. In this paper, authors present a printed electronics-based approach to fabrication of the $\mathrm{pH}$-sensitive potentiometric electrodes. Pastes prepared for screen printing of the functional layer of the transceivers were based on the previously developed conductive graphene composites [28] with addition of the ruthenium (IV) oxide as the proton-sensitive phase, of which response mechanism was described in detail elsewhere [29, 30]. 
Briefly, after immersion of the metal oxide in the solution, protons and hydroxide ions are bound to the oxygen ions in the metal oxide crystal lattice and with the surface cations, respectively, resulting in covering the metal oxide surface with the hydroxyl groups. Then, exchange of the protons between the hydroxyl groups and the solution occurs and thus the electrical potential of the surface is determined by the $\mathrm{H}^{+} / \mathrm{OH}^{-}$ions balance in the solution [30-32]. There are also reports [33] on the $\mathrm{pH}$-sensitive electrodes based on the mixture of the $\mathrm{RuO}_{2}$ with another, chemically inert oxide, aimed at reduction of material costs derived from the $\mathrm{RuO}_{2}$ expensiveness. In these works however, sensors' performance drop was reported.

Graphene also exhibits similar properties that allow for pH sensing, as described by Lei et al. [34] and Ang et al. [35]. $\mathrm{H}_{3} \mathrm{O}^{+}$and $\mathrm{OH}^{-}$ions from the solution are adsorbed on the graphene surface depending on the solution's $\mathrm{pH}$. At the same time, graphene nanoplatelets (GNP) are much cheaper than $\mathrm{RuO}_{2}$.

Based on these facts, successful implementation of graphene for $\mathrm{pH}$ sensors fabrication and reports on the binary metal oxide electrodes [36], authors investigated a possibility of employment of $\mathrm{RuO}_{2} / \mathrm{GNP}$ nanocomposite for potential cost-effective $\mathrm{pH}$ sensor fabrication. Presented work was aimed at resulting in both $\mathrm{pH}$ sensing transceiver and satisfying utility requirements, such as production costs optimization, manufacturing process simplicity, and sensor's flexibility.

\section{Materials and Methods}

2.1. Materials. Poly(methyl methacrylate) (PMMA) with average molecular weight $M_{w}=350,000$; diethylene glycol butyl ether acetate $\geq 99 \%$ pure; toluene $\geq 99.3 \%$ pure and citric acid 99\% pure were purchased from Sigma-Aldrich. Ruthenium(IV) oxide Premion submicron powder with $74 \% \mathrm{Ru}$ was acquired from Alfa Aesar (Germany). Sodium hydroxide was purchased from POCH S.A. (Poland).

Graphene nanoplatelets M-25 with $25 \mu \mathrm{m}$ average diameter and typical surface area of 120 to $150 \mathrm{~m}^{2} \cdot \mathrm{g}^{-1}$ were acquired from XG Sciences Inc. (USA). Silver paste L-121 based on silver microflakes was acquired from ITME (Poland). The insulating UV-curable 5018G and heat-curable 8155 pastes were bought from DuPont. Polyester (PET) foil Melinex 453 with a thickness of $100 \mu \mathrm{m}$ was delivered by TEKRA (USA).

2.2. Preparation of Printing Pastes. Screen printing pastes for $\mathrm{pH}$-sensitive layers were composed of PMMA polymer matrix, graphene nanoplatelets, and ruthenium oxide powders. Firstly $8 \mathrm{wt} \%$ PMMA resin was prepared by dissolving the PMMA granulate in diethylene glycol butyl ether by means of magnetic stirrer ( 48 hours in $60^{\circ} \mathrm{C}$ ). Secondly, $12 \mathrm{wt} \%$ graphene nanoplatelets paste was prepared by adding the graphene platelets to the $8 \mathrm{wt} \%$ PMMA resin prepared earlier. Paste was rolled two times in the three-roll-mill with silicon carbide $(\mathrm{SiC})$ rollers and $5 \mu \mathrm{m}$ gap to obtain homogenous compositions without agglomerates. After receiving suitable graphene nanoplatelets paste, the paste was divided into 6 parts and final set of 6 different (10wt\%, $20 \mathrm{wt} \%$,
TABLE 1: Compositions of screen printing $\mathrm{RuO}_{2} / \mathrm{GNP} / \mathrm{PMMA}$ pastes for $\mathrm{pH}$-sensitive layers.

\begin{tabular}{lccc}
\hline Paste & $\mathrm{RuO}_{2}$ content, wt $\%$ & Graphene paste $12 \mathrm{wt} \%, \mathrm{~g}$ & $\mathrm{RuO}_{2}, \mathrm{~g}$ \\
\hline 1 & 10 & 1.8 & 0.2 \\
2 & 20 & 1.6 & 0.4 \\
3 & 30 & 1.4 & 0.6 \\
4 & 40 & 1.2 & 0.8 \\
5 & 50 & 1.0 & 1.0 \\
6 & 60 & 0.8 & 1.2 \\
\hline
\end{tabular}

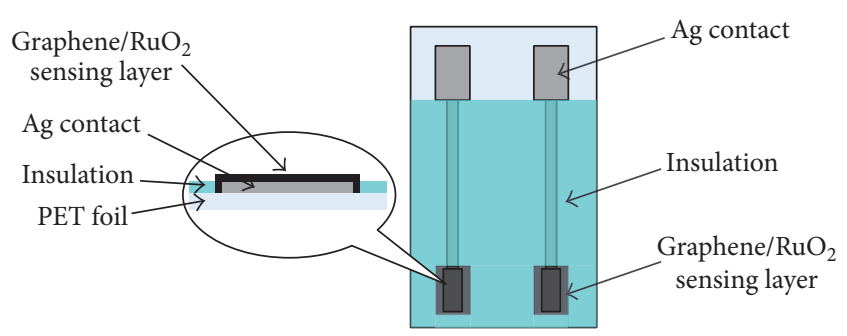

FIgURE 1: Schematic diagram of the sensor structure.

$30 \mathrm{wt} \%, 40 \mathrm{wt} \%, 50 \mathrm{wt} \%$, and $60 \mathrm{wt} \%$ ) compositions with ruthenium oxide was prepared according to Table 1. Also, $\mathrm{RuO}_{2}$ paste was prepared by $40 \mathrm{wt} \%$ addition of $\mathrm{RuO}_{2}$ to the $8 \mathrm{wt} \%$ PMMA resin. After adding appropriate amounts of $\mathrm{RuO}_{2}$, each sample was rolled again with the three-roll-mill.

2.3. Fabrication of Sensors. Sensors were fabricated on the PET foil and consisted of three subsequently printed layers (as shown in Figure 1) made by means of Ami Presco 485 screen printer. Firstly, silver contacts and conductive paths were deposited with the use of commercially available silver screen printing paste (L-121). Secondly, $\mathrm{pH}$-sensitive $\mathrm{GNP} / \mathrm{RuO}_{2}$ layers were printed prepared as described in the section above. Eventually, dielectric layer was printed on the top of silver paths and around $\mathrm{pH}$-sensitive areas to insulate conductive paths from the electrolyte during measurements. Silver conductive layers and $\mathrm{GNP} / \mathrm{RuO}_{2} \mathrm{pH}$-sensitive layers were cured in $120^{\circ} \mathrm{C}$ for 30 minutes in a chamber dryer. The insulating layers were printed with two different pastes: heatcurable and UV-curable. The former was cured in $120^{\circ} \mathrm{C}$ for 10 minutes and the latter was cured in UV dryer with the dose around $700 \mathrm{~mJ} \cdot \mathrm{cm}^{-2}$. All sensor layers were printed with the use of $77 \mathrm{~T}$ polyester screens. The $\mathrm{pH}$-sensitive layer based on GNP and $\mathrm{RuO}_{2}$ had a thickness of about $10 \mu \mathrm{m}$, the insulating layer of about $20 \mu \mathrm{m}$, and silver layer of about $15 \mu \mathrm{m}$.

2.4. Measurements. Electrochemical potentials were measured using EMF-16 (Lawson Labs Inc., USA) mV-meter with the following galvanic cell: $\mathrm{Ag} / \mathrm{AgCl}_{(\mathrm{s})}, \mathrm{KCl}(4 \mathrm{M}) /$ bridge electrolyte/sample solution/( $\left.\mathrm{RuO}_{2} / \mathrm{GNP} / \mathrm{PMMA}\right) / \mathrm{Ag}$. The bridge electrolyte of the double-junction reference electrode was $1 \mathrm{M} \mathrm{KCl}$. Simultaneously, $\mathrm{pH}$ of the solution was measured using $\mathrm{CP}-505 \mathrm{pH}-$ meter (Elmetron, Poland). UV-exposure tests were performed using FC-100/D UV-A $(365 \mathrm{~nm})$ lamp (Spectronics Inc., USA). Calibration of the 


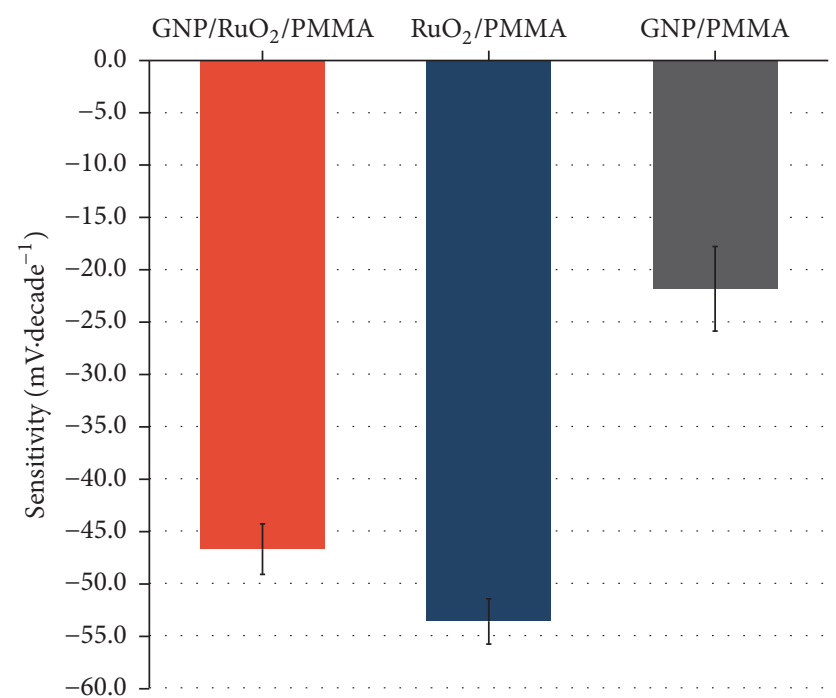

Figure 2: Comparison of the GNP, $\mathrm{RuO}_{2}$ and $\mathrm{GNP} / \mathrm{RuO}_{2}$-based composites for fabrication of $\mathrm{pH}$ sensors.

sensors was conducted in $50 \mathrm{mM} \cdot \mathrm{L}^{-1}$ citric acid buffer solution with gradually added $\mathrm{NaOH}$ solution for $\mathrm{pH}$ increment. For each $\mathrm{RuO}_{2}$ concentration in paste, seven electrodes were calibrated, assuming mean calculated linear regression slope as the sensitivity. Then, calibrated sensors were bent perpendicularly on custom-made bending machine for 10,000 cycles and calibrated again to assess their flexibility.

\section{Results and Discussion}

3.1. Dependency of Sensitivity on $\mathrm{RuO}_{2}$ Content. To evaluate applicability of the described composites for $\mathrm{pH}$ sensors, calibration of the GNP/PMMA, $\mathrm{RuO}_{2} / \mathrm{PMMA}$, and GNP/ $/ \mathrm{RuO}_{2} / \mathrm{PMMA}\left(60 \mathrm{wt} \% \mathrm{RuO}_{2}\right)$ was carried out as described in Section 2.4. Comparison of obtained sensitivity values is shown in Figure 2. As expected, $\mathrm{RuO}_{2} / \mathrm{PMMA}$ composite exhibited greater sensitivity than other materials $\left(-53.65 \mathrm{mv} \cdot \mathrm{pH}^{-1}\right)$ and GNP/PMMA the lowest. In GNP/ $\mathrm{RuO}_{2} /$ PMMA sensitivity drop was observed, but to verify prospective material costs optimization, influence of the component proportions was further investigated.

Figure 3 shows calibration curves for the sensors prepared as in Sections 2.2 and 2.3. (sensors with UV-curable insulating layer). Linear response of the sensors was observed in $\mathrm{pH}$ range of 2.18-6.82. Above this range, next additions of $\mathrm{NaOH}$ resulted in buffer solution $\mathrm{pH}$ exceeding its linear range. Calculated sensitivity values are presented in Figure 4.

As expected, sensitivity was observed to be the highest for the electrodes with the highest $\mathrm{RuO}_{2}$ content in paste, although this dependency did not exhibit linear character.

It was observed that, for 10,20 and $30 \mathrm{wt} \%$ of $\mathrm{RuO}_{2}$ content in the printing paste, sensitivity of the sensors is uniform within margin of error. Above $30 \mathrm{wt} \%$, the value of sensitivity significantly increases (Figure 4 ). This thresholdlike effect was observed more distinctly on logarithmic scale (Figure 5). As it was previously proven when considering conductivity of the printed nanocarbon composites [37, 38],

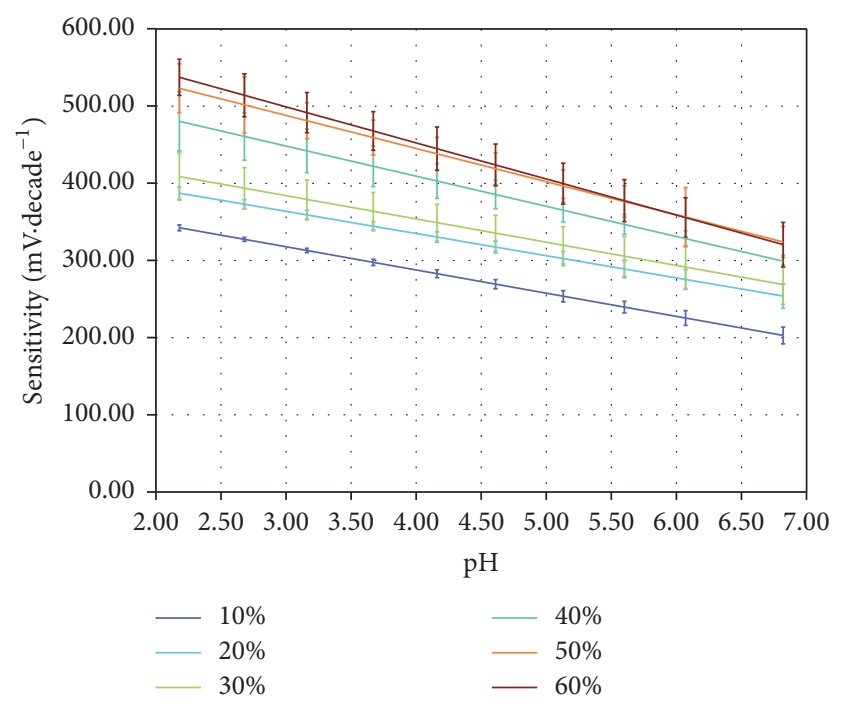

FIGURE 3: Calibration of the fabricated $\mathrm{pH}$-metric sensors; linear response in $\mathrm{pH}$ range $2.18-6.82$.

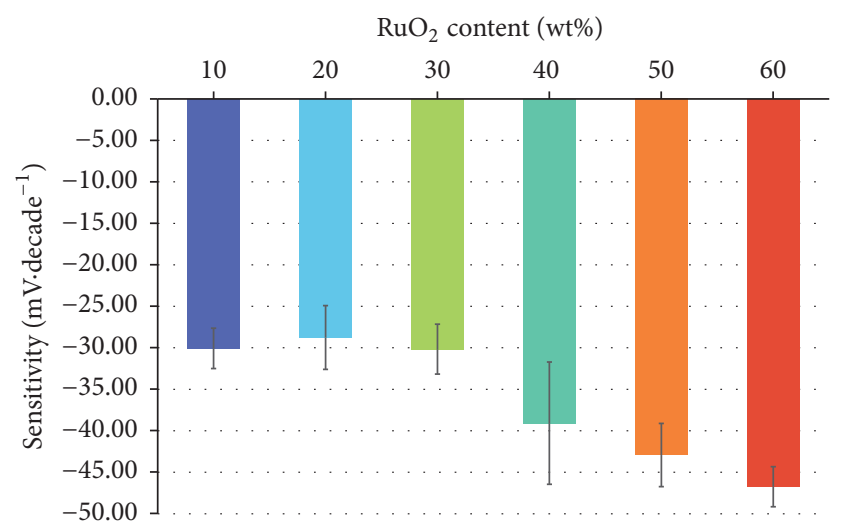

FIGURE 4: Comparison of the sensitivity calculated for the examined sensors.

some properties of this kind of composites depend on the so-called percolation threshold. According to the percolation theory, properties such as conductivity or permeability are exhibited by a composite only above certain content of the proper phase [39] -in the case of the examined sensors$\mathrm{RuO}_{2}$. This threshold can be interpreted as the minimum volume of the $\mathrm{RuO}_{2}$ in the composite, sufficient to form stable connections with conductive graphene phase which is needed for correct translation of the proton adsorption by $\mathrm{RuO}_{2}$ to the change of electric potential of the printed electrode.

To determine percolation threshold for sensitivity to $\mathrm{pH}$ changes, sensitivity of the $10-30 \%$ samples was approximated by the mean value as all the values lie within the same range of confidence (Figure 3). Next, the values obtained for $40-$ $60 \%$ samples were used to fit the line in logarithmic scale (Figure 5). Calculated dependency (coefficient of determination $R^{2}=97.8 \%$ ) of sensitivity on $\mathrm{RuO}_{2}$ wt $\%$ content was

$$
s=-27.162 \cdot \operatorname{In}(C)-58.896,
$$




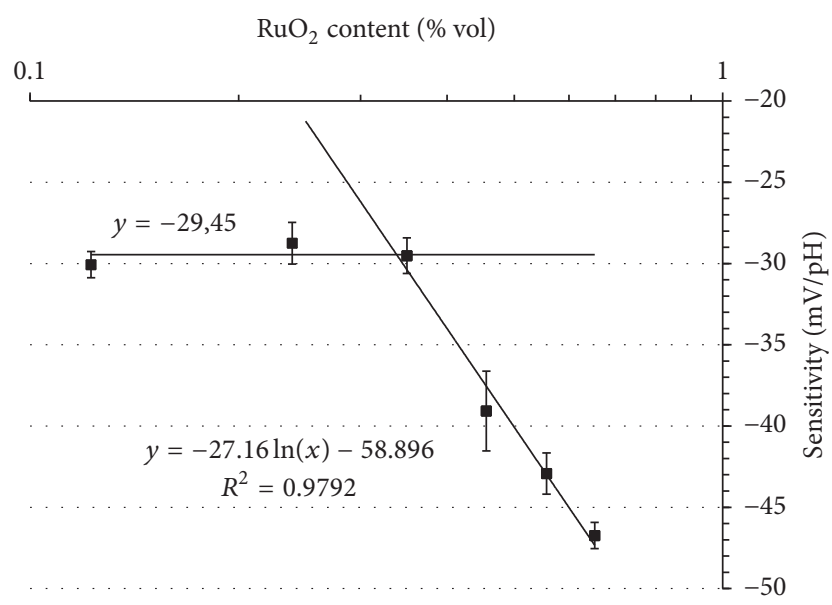

Figure 5: Percolation threshold for sensitivity to $\mathrm{pH}$ changes.

where $s$ is sensitivity $\left[\mathrm{mV} \cdot \mathrm{decade}^{-1}\right]$ and $\mathrm{C}$ is $\mathrm{RuO}_{2}$ content [vol\%].

Thus, the percolation threshold was determined as the cross-section point of the constant sensitivity line and linear increase line. The value obtained from solving (1) was $33.82 \mathrm{vol} \%$.

\subsection{Influence of the UV-Irradiation on the Sensors' Perfor-} mance. As the $\mathrm{pH}$ sensing properties of $\mathrm{RuO}_{2}$ are reported to be strongly influenced by the UV radiation [40] and flexible $\mathrm{pH}$ sensors may find application in many fields which implicate exposure to such radiation (e.g., environment monitoring, sport activity tracking, etc.), the dependency of the sensors' indications on this condition was investigated employing sensors with temperature-cured insulating layer and $40 \mathrm{wt} \% \mathrm{RuO}_{2}$ content in paste. Calibration of these sensors was performed as described in Section 2.4 before any exposure to the UV radiation and after irradiation by dose around $1300 \mathrm{~mJ} \cdot \mathrm{cm}^{-2}$. Thus, sensitivity values for no UV exposure, 700 and $1300 \mathrm{~mJ} \cdot \mathrm{cm}^{-2}$ doses, were obtained (Figure 6). Obtained results indicated notably that above certain level of UV exposure the sensitivity increased even above the basic level $\left(\Delta s=3.57 \mathrm{mV} \cdot \mathrm{pH}^{-1}\right)$. It can be explained based on the findings reported in the section above. Since UV radiation is confirmed to cause degradation of PMMA [41, 42], dose high enough to initiate this process may lead to change of the volumetric proportions of the functional material in the electrode layer. Thus, UV-treated sensors fabricated with paste of lower $\mathrm{RuO}_{2}$ content exhibited higher sensitivity than sensors fabricated with higher $\mathrm{RuO}_{2}$ content and not exposed to higher doses of UV radiation (50\% and $60 \%$ samples).

3.3. Flexibility Tests. Performance of the sensors was also tested with respect to their flexibility. Calculated changes of the sensitivity after 10,000 cycles of bending are shown in Table 2. The results may indicate that the number of bending cycles applied is close to the electrodes' material fatigue limit, since the bending caused significant drop in performance in

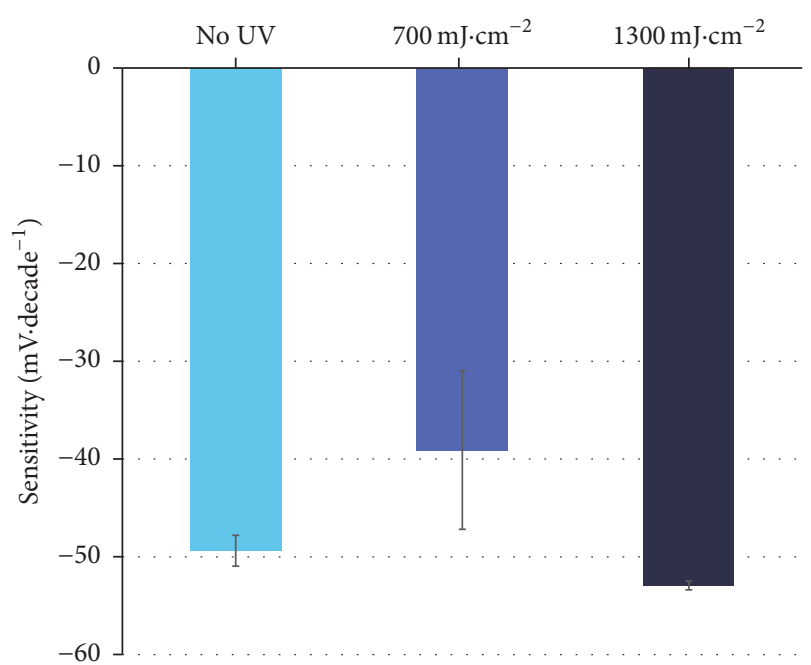

FIGURE 6: Sensors' sensitivity with respect to the UV exposition.

TABLe 2: Sensors' sensitivity before and after 10,000 cycles of bending.

\begin{tabular}{|c|c|c|c|}
\hline \multirow{2}{*}{$\mathrm{RuO}_{2}$ content $[\mathrm{wt} \%]$} & \multicolumn{2}{|c|}{ Sensitivity $\left[\mathrm{mV} \cdot \mathrm{pH}^{-1}\right]$} & \multirow{2}{*}{ Sensitivity change } \\
\hline & Before & After & \\
\hline $10 \%$ & -29.83 & -13.14 & $56.0 \%$ \\
\hline $20 \%$ & -26.03 & -18.82 & $27.7 \%$ \\
\hline $30 \%$ & -27.86 & -30.41 & $-9.2 \%$ \\
\hline $40 \%$ & -46.01 & -46.26 & $-0.5 \%$ \\
\hline $50 \%$ & -42.90 & -34.26 & $20.1 \%$ \\
\hline $60 \%$ & -46.17 & -50.61 & $-9.6 \%$ \\
\hline
\end{tabular}

three out of six cases $(10 \%, 20 \%$, and $50 \%$ samples). In the case of other samples, the observed increase in sensitivity may derive from the compression of the composite before reaching the fatigue limit, as the compressed composite would be characterized by greater $\mathrm{RuO}_{2}$ content in the layer's volume (see Section 3.2). This can be observed on the SEM images (Figure 7) of the electrode's surface taken for the sample before (a) and after (b) the bending test. On the SEM image of the sample after bending, there is area of significant $\mathrm{RuO}_{2}$ particles' thinning. Supposedly, it is due to the fact that cracking of the graphene layer revealed the surface that was not covered by $\mathrm{RuO}_{2}$ during preparation of the composite paste.

\section{Conclusions}

Screen printed $\mathrm{pH}$ sensors based on the ruthenium (IV) oxide/graphene nanoplatelets composite were fabricated and examined, exhibiting wide linear range $(\mathrm{pH} 2.18-6.82)$ and good reproducibility $( \pm 5.41 \%$ standard deviation for $60 \%$ paste). Thresholding effect of the $\mathrm{RuO}_{2}$ content on sensitivity was observed, which was explained with respect to percolation theory and probability of the $\mathrm{RuO}_{2}$ connecting with the conductive phase of the composite. Moreover, UVirradiation was found to influence the sensors' performance positively or negatively, depending on the radiation dose, 


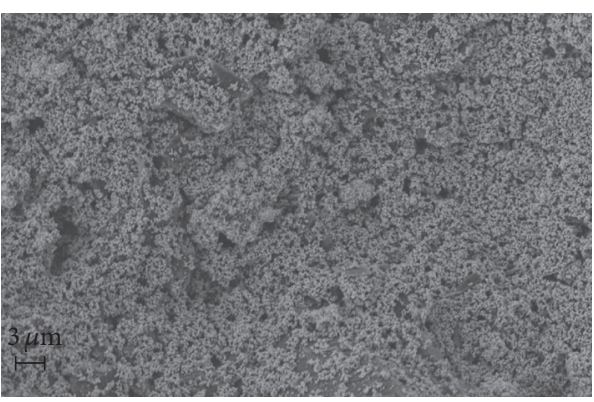

(a)

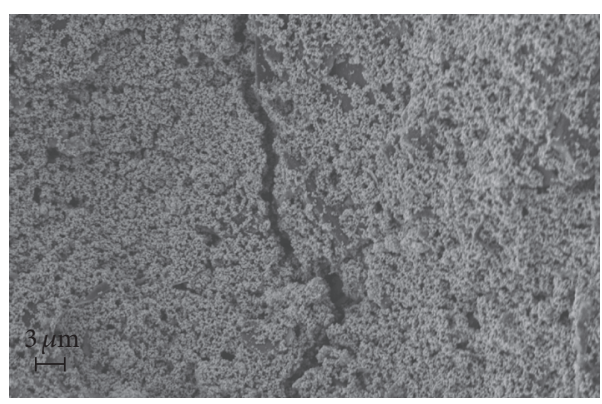

(b)

FIGURE 7: Comparison of the SEM images of $\mathrm{RuO}_{2} /$ GNP/PMMA composite: before (a) and after (b) bending test.

which also was ascribed to the change in the composite proportions. As the percolation threshold was determined for $\mathrm{RuO}_{2}$ content and sensitivity-enhancing effect of the UV radiation was observed, this investigation may lead to optimization of the $\mathrm{RuO}_{2}$ content and thus minimizing the production costs of the sensors. Electrodes were also tested in terms of their flexibility and fatigue resulting in significant performance drop was identified as around 10,000 cycles of perpendicular bending which indicates good endurance for sensors' deformation.

\section{Competing Interests}

The authors declare that there is no conflict of interests regarding the publication of this paper.

\section{References}

[1] E. B. Secor, B. Y. Ahn, T. Z. Gao, J. A. Lewis, and M. C. Hersam, "Rapid and versatile photonic annealing of graphene inks for flexible printed electronics," Advanced Materials, vol. 27, no. 42, pp. 6683-6688, 2015.

[2] Y. H. Jung, T.-H. Chang, H. Zhang et al., "High-performance green flexible electronics based on biodegradable cellulose nanofibril paper," Nature Communications, vol. 6, article 7170, 2015.

[3] Z. Wang, W. Wang, Z. Jiang, and D. Yu, "Low temperature sintering nano-silver conductive ink printed on cotton fabric as printed electronics," Progress in Organic Coatings, vol. 101, pp. 604-611, 2016.

[4] K. K. Adhikari, Y. Jung, H. Park, G. Cho, and N.-Y. Kim, "Silver-nanoparticle-based screen-printing and film characterization of a disposable, dual-band, bandstop filter on a flexible polyethylene terephthalate substrate," Journal of Nanomaterials, vol. 2015, Article ID 810150, 8 pages, 2015.

[5] D. Maddipatla, B. B. Narakathu, S. G. R. Avuthu et al., "A novel flexographic printed strain gauge on paper platform," in Proceedings of the IEEE SENSORS, pp. 1-4, IEEE, Busan, South Korea, November 2015.

[6] C. M. Homenick, R. James, G. P. Lopinski et al., "Fully printed and encapsulated SWCNT-based thin film transistors via a combination of R2R gravure and inkjet printing," ACS Applied Materials \& Interfaces, vol. 8, no. 41, pp. 27900-27910, 2016.

[7] C. Kapnopoulos, E. D. Mekeridis, L. Tzounis et al., "Gravure printed organic photovoltaic modules onto flexible substrates consisting of a P3HT: PCBM photoactive blend," Materials Today: Proceedings, vol. 3, no. 3, pp. 746-757, 2016.

[8] T. Laine-Ma, P. Ruuskanen, S. Pasanen, and M. Karttunen, "Pad printing of polymeric silver ink conductors on thermoplastic foils," Circuit World, vol. 42, no. 4, pp. 170-177, 2016.

[9] A. Kamyshny and S. Magdassi, "Conductive nanomaterials for printed electronics," Small, vol. 10, no. 17, pp. 3515-3535, 2014.

[10] S. Jung, A. Sou, E. Gili, and H. Sirringhaus, "Inkjet-printed resistors with a wide resistance range for printed read-only memory applications," Organic Electronics: Physics, Materials, Applications, vol. 14, no. 3, pp. 699-702, 2013.

[11] P. H. Lau, K. Takei, C. Wang et al., "Fully printed, high performance carbon nanotube thin-film transistors on flexible substrates," Nano Letters, vol. 13, no. 8, pp. 3864-3869, 2013.

[12] V. Subramanian, J. Chang, and F. Liao, "Printed organic chemical sensors and sensor systems," in Applications of Organic and Printed Electronics, pp. 157-177, Springer US, 2013.

[13] N. Matsuhisa, M. Kaltenbrunner, T. Yokota et al., "Printable elastic conductors with a high conductivity for electronic textile applications," Nature Communications, vol. 6, 2015.

[14] N. Komoda, M. Nogi, K. Suganuma, H. Koga, and K. Otsuka, "Silver nanowire antenna printed on polymer and paper substrates," in Proceedings of the 12th IEEE International Conference on Nanotechnology (NANO '12), IEEE, Birmingham, UK, August 2012.

[15] A. G. Kelly, D. Finn, A. Harvey, T. Hallam, and J. N. Coleman, "All-printed capacitors from graphene-BN-graphene nanosheet heterostructures," Applied Physics Letters, vol. 109, no. 2, Article ID 023107, 2016.

[16] D. Jeschke, M. Niemann, and K. Krüger, "In-situ blending of inkjet-printed thick-film resistors," in Proceedings of the Additional Conferences (Device Packaging, HiTEC, HiTEN, \& CICMT), pp. 211-220, September 2013.

[17] G. Wroblewski, K. Kielbasinski, T. Stapinski et al., "Graphene platelets as morphology tailoring additive in carbon nanotube transparent and flexible electrodes for heating applications," Journal of Nanomaterials, vol. 2015, Article ID 316315, 8 pages, 2015.

[18] K. Kim, G. Kim, B. R. Lee et al., "High-resolution electrohydrodynamic jet printing of small-molecule organic light-emitting diodes," Nanoscale, vol. 7, no. 32, pp. 13410-13415, 2015.

[19] A. Hayat and J. L. Marty, "Disposable screen printed electrochemical sensors: tools for environmental monitoring," Sensors, vol. 14, no. 6, pp. 10432-10453, 2014.

[20] S. Mross, T. Zimmermann, N. Winkin, M. Kraft, and H. Vogt, "Integrated multi-sensor system for parallel in-situ monitoring 
of cell nutrients, metabolites, cell density and $\mathrm{pH}$ in biotechnological processes," Sensors and Actuators, B: Chemical, vol. 236, pp. 937-946, 2015.

[21] B. Melai, P. Salvo, N. Calisi et al., "A graphene oxide $\mathrm{pH}$ sensor for wound monitoring," in Proceedings of the 38th Annual International Conference of the IEEE Engineering in Medicine and Biology Society (EMBC '16), pp. 1898-1901, IEEE, Orlando, Fla, USA, August 2016.

[22] K. S. Johnson, H. W. Jannasch, L. J. Coletti et al., "Deep-Sea DuraFET: a pressure tolerant $\mathrm{pH}$ sensor designed for global sensor networks," Analytical Chemistry, vol. 88, no. 6, pp. 32493256, 2016.

[23] P. Jiang, H. Xia, Z. He, and Z. Wang, "Design of a water environment monitoring system based on wireless sensor networks," Sensors, vol. 9, no. 8, pp. 6411-6434, 2009.

[24] L. O'Sullivan, R. P. Ross, and C. Hill, "Potential of bacteriocinproducing lactic acid bacteria for improvements in food safety and quality," Biochimie, vol. 84, no. 5-6, pp. 593-604, 2002.

[25] J. Saranya, L. Rajendran, and M. U. Maheswari, "A theoretical model of $\mathrm{pH}$-based potentiometric biosensor based on immobilized enzyme membrane," American Journal of Analytical Chemistry, vol. 7, no. 4, pp. 363-377, 2016.

[26] E. M. McConnell, R. Bolzon, P. Mezin, G. Frahm, M. Johnston, and M. C. DeRosa, "PHAST (pH-Driven Aptamer Switch for Thrombin) Catch-and-Release of Target Protein," Bioconjugate Chemistry, vol. 27, no. 6, pp. 1493-1499, 2016.

[27] E. Voitechovic, D. Kirsanov, and A. Legin, "An approach to potentiometric sensing of sugars: Baker's yeast assisted $\mathrm{pH}$ electrode," Sensors and Actuators, B: Chemical, vol. 225, pp. 209$212,2016$.

[28] G. Wróblewskia, M. Słomaa, D. Janczak, A. Młozniakb, and M. Jakubowska, "Influence of carbon nanoparticles morphology on physical properties of polymer composites," Acta Physica Polonica A, vol. 125, no. 4, pp. 861-863, 2014.

[29] P. Kurzweil, "Metal oxides and ion-exchanging surfaces as $\mathrm{pH}$ sensors in liquids: state-of-the-art and outlook," Sensors, vol. 9, no. 6, pp. 4955-4985, 2009.

[30] P. Kurzweil, "Precious metal oxides for electrochemical energy converters: pseudocapacitance and $\mathrm{pH}$ dependence of redox processes," Journal of Power Sources, vol. 190, no. 1, pp. 189-200, 2009.

[31] S. Al-Hilli and M. Willander, "The $\mathrm{pH}$ response and sensing mechanism of n-type $\mathrm{ZnO}$ /electrolyte interfaces," Sensors, vol. 9, no. 9, pp. 7445-7480, 2009.

[32] M. Chen, Y. Jin, X. Qu, Q. Jin, and J. Zhao, "Electrochemical impedance spectroscopy study of $\mathrm{Ta}_{2} \mathrm{O}_{5}$ based EIOS $\mathrm{pH}$ sensors in acid environment," Sensors and Actuators B: Chemical, vol. 192, pp. 399-405, 2014.

[33] L. A. Pocrifka, C. Gonçalves, P. Grossi, P. C. Colpa, and E. C. Pereira, "Development of $\mathrm{RuO}_{2}-\mathrm{TiO}_{2}$ (70-30) mol\% for $\mathrm{pH}$ measurements," Sensors and Actuators, B: Chemical, vol. 113, no. 2, pp. 1012-1016, 2006.

[34] N. Lei, P. Li, W. Xue, and J. Xu, "Simple graphene chemiresistors as $\mathrm{pH}$ sensors: fabrication and characterization," Measurement Science and Technology, vol. 22, no. 10, Article ID 107002, 2011.

[35] P. K. Ang, W. Chen, A. T. S. Wee, and P. L. Kian, "Solutiongated epitaxial graphene as $\mathrm{pH}$ sensor," Journal of the American Chemical Society, vol. 130, no. 44, pp. 14392-14393, 2008.

[36] L. Manjakkal, K. Cvejin, J. Kulawik, K. Zaraska, D. Szwagierczak, and R. P. Socha, "Fabrication of thick film sensitive $\mathrm{RuO}_{2}-\mathrm{TiO}_{2}$ and $\mathrm{Ag} / \mathrm{AgCl} / \mathrm{KCl}$ reference electrodes and their application for $\mathrm{pH}$ measurements," Sensors and Actuators, B: Chemical, vol. 204, pp. 57-67, 2014.

[37] X. Wu, S. Qi, J. He, and G. Duan, "High conductivity and low percolation threshold in polyaniline/graphite nanosheets composites," Journal of Materials Science, vol. 45, no. 2, pp. 483$489,2010$.

[38] K. Kalaitzidou, H. Fukushima, and L. T. Drzal, "A new compounding method for exfoliated graphite-polypropylene nanocomposites with enhanced flexural properties and lower percolation threshold," Composites Science and Technology, vol. 67, no. 10, pp. 2045-2051, 2007.

[39] S. R. Broadbent and J. M. Hammersley, "Percolation processes: I. Crystals and mazes," Mathematical Proceedings of the Cambridge Philosophical Society, vol. 53, no. 3, pp. 629-641, 1957.

[40] Y.-H. Liao and J.-C. Chou, "Preparation and characteristics of ruthenium dioxide for $\mathrm{pH}$ array sensors with real-time measurement system," Sensors and Actuators, B: Chemical, vol. 128, no. 2, pp. 603-612, 2008.

[41] S. Eve and J. Mohr, "Study of the surface modification of the PMMA by UV-radiation," Procedia Engineering, vol. 1, no. 1, pp. 237-240, 2009.

[42] T. Çaykara and O. Güven, "UV degradation of poly(methyl methacrylate) and its vinyltriethoxysilane containing copolymers," Polymer Degradation and Stability, vol. 65, no. 2, pp. 225229, 1999. 


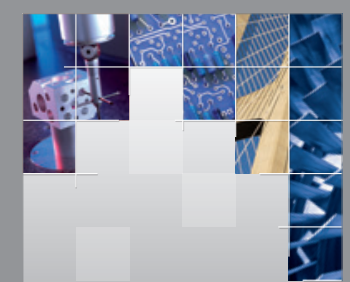

\section{Enfincering}
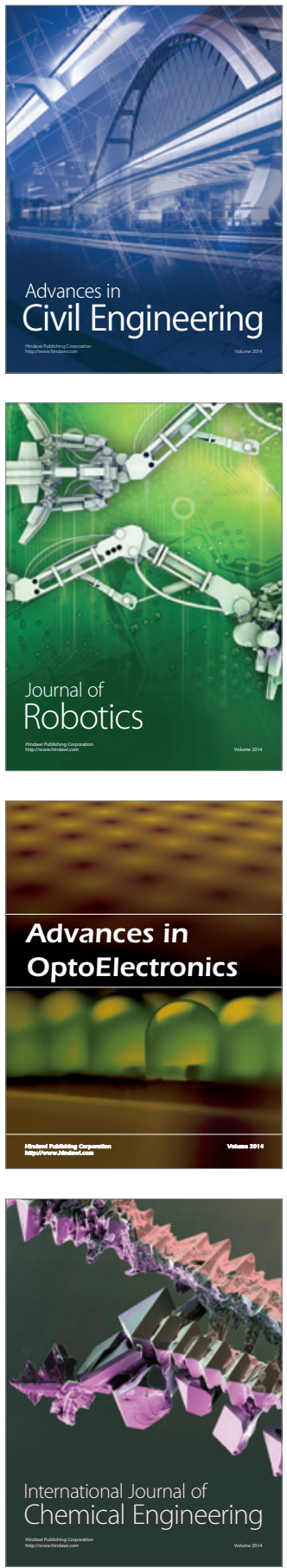

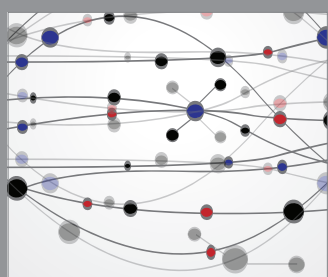

The Scientific World Journal

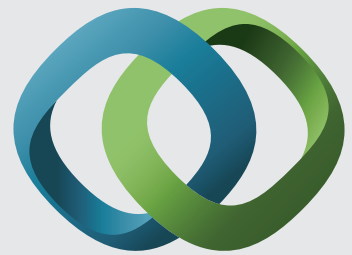

\section{Hindawi}

Submit your manuscripts at

https://www.hindawi.com
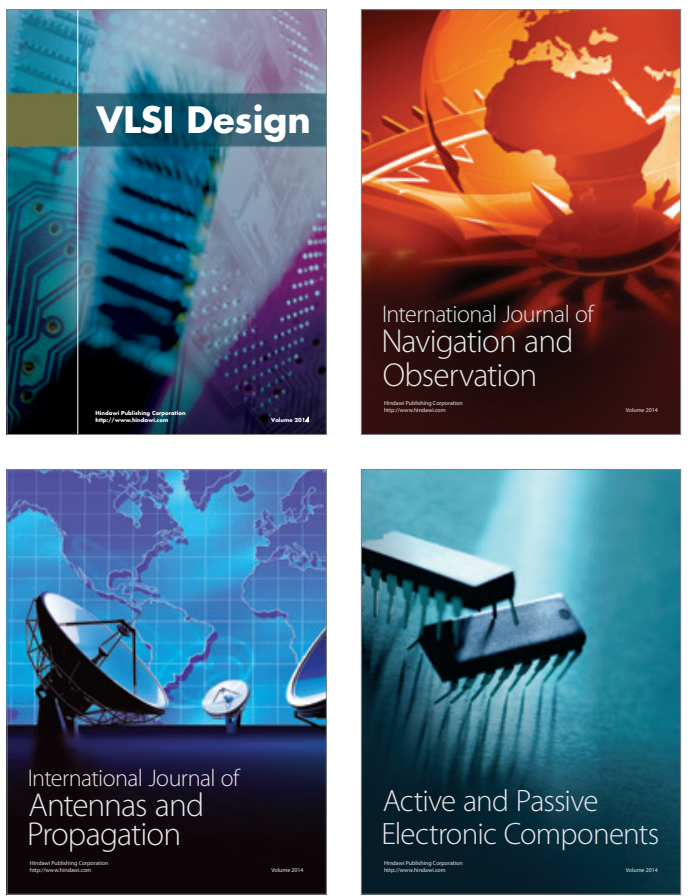
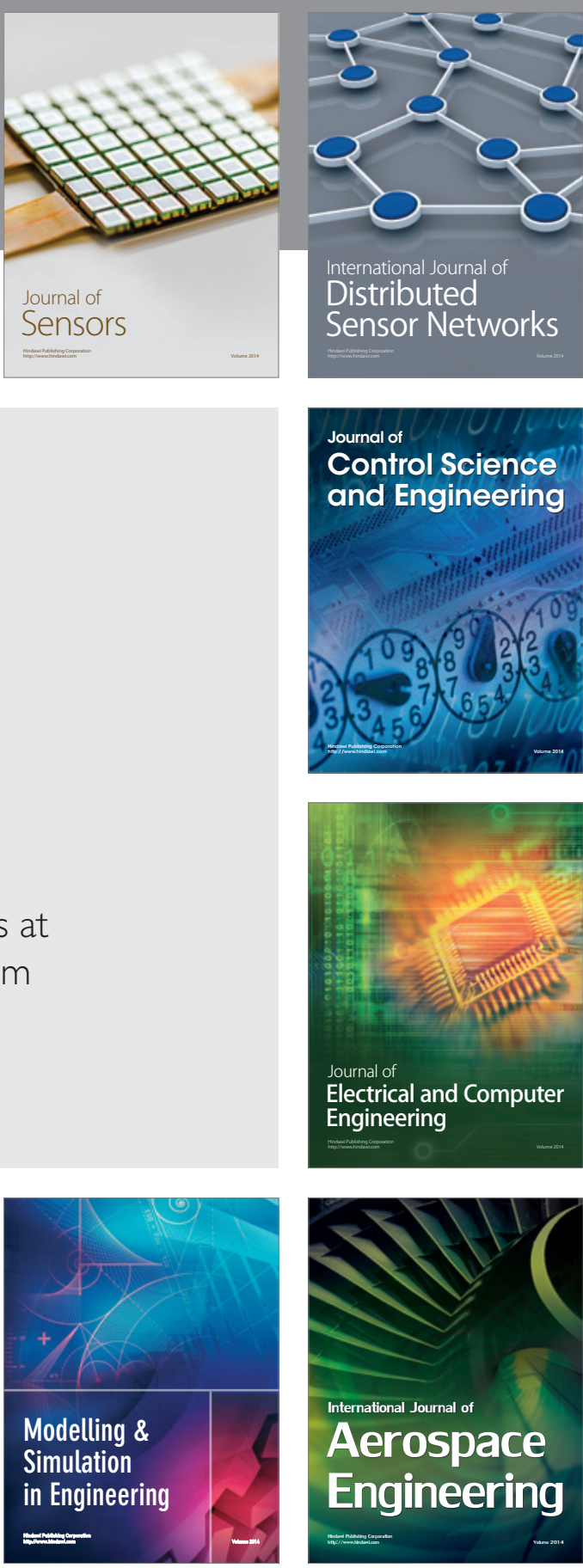

International Journal of

Distributed

Sensor Networks

$-$

Joumal of

Control Science

and Engineering
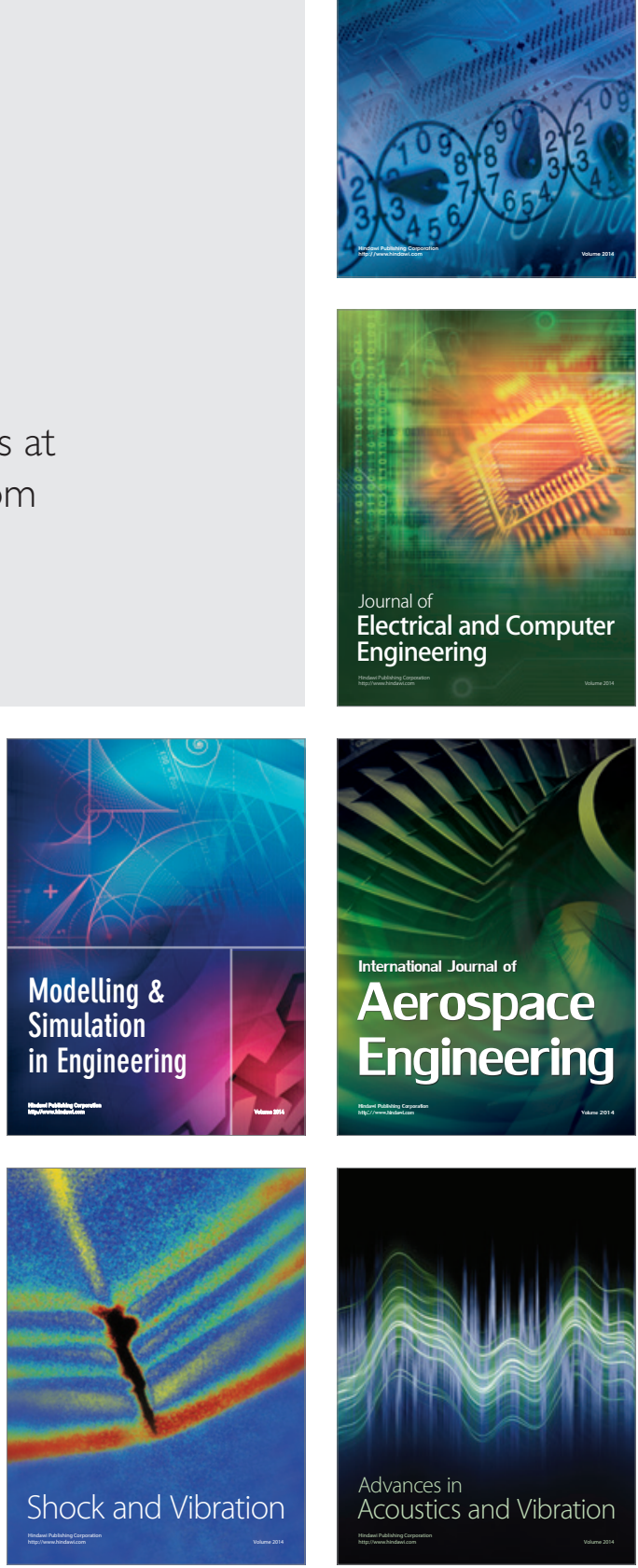